\title{
Functionalized gold nanoparticles for inhibition of vascular endothelial growth factor in arthritic patients
}

\begin{abstract}
The idea behind this study is the use of Nanotechnological approaches in treatment of arthritic patients through targeting of Vascular Endothelial Growth Factor A (VEGFA) as angiogenic factor. Anti-Vascular Endothelial Growth Factor A/Gold nanoparticles (antiVEGFA /GNPs)conjugate have been prepared and applied to serum of Osteoarthritis (OA) and Rheumatoid Arthritis (RA) patients for scavenger of VEGFA antigen present in serum. The level of VEGFA in RA and OA patients has been estimated before and after incubation of serum of arthriticpatients with (anti-VEGFA /GNPs) anti-VEGFA/GNPs conjugate. It assumed that the anti-VEGFA/GNPs conjugate bind with VEGFA antigen so it will inhibit proliferation and angiogenesis in serum of arthritic patients as primary treatment of arthritis. The characterization of both anti-VEGFA/GNPs conjugate and gold nanoparticles (GNPs) such as particle size, zeta potential (ZP), transmission electron microscopy (TEM) and FTIR were investigated. This anti-VEGFA/GNPs conjugate has been applied to "thirty three" serum samples of human patients with OA and RA in vitro. The Optimization of antiVEGFA/GNPs gives that $100 \mathrm{ng} / \mathrm{mL}$ is an optimum concentration of anti-VEGFA/GNPs conjugate. It can decrease the level of VEGFA in serum of human patients upon incubation for $2 \mathrm{~h}$ rat room temperature. The anti-VEGFA/GNPs conjugate gives cure percent $59 \%$ and $62 \%$ in OA and RA patients 'respectively through a single addition of anti-VEGFA/ GNPs conjugate to serum that was validated by ELISA method. This technique open new modality and hope for OA and RA patients using novel nanotechnological approach.
\end{abstract}

Keywords: Gold nanoparticles, Rheumatoid arthritis, Osteoarthritis, Vascular endothelial growth factor, Nanoconjugation
Volume 2 Issue 4 - 2015

\author{
Mona R El-Ansary,' Taher A Salah Eldin, ${ }^{2}$ Ola \\ MS Ali, ${ }^{3}$ Adel M Elsayed, ${ }^{4}$ Hisham A Elshoky ${ }^{2}$ \\ 'Department Biochemistry, Modern University for Technology \\ and Information, Egypt \\ ${ }^{2}$ Nanotechnology and Advanced Materials Central Lab, Egypt \\ ${ }^{3}$ Department Biochemistry, Al-Azhar University, Egypt \\ ${ }^{4}$ Department of Internal Medicine, Ain Shams University, Egypt
}

Correspondence: Taher A Salah Eldin, Nanotechnology \& Advanced Materials Central Lab,Agriculture Research Center. 9 Elgamaa St., P.O. 588orman, Giza, Egypt, Tel 201001000000, Fax 202357|3250 Email tIsaleh@hotmail.com

Received: October 24, 2015 | Published: November 20, 2015
Abbreviations:Anti-VEGFA/GNPs, Anti-Vascular Endothelial Growth Factor A/Gold nanoparticles; RA, Rheumatoid Arthritis; OA, Osteoarthritis; TEM, Transmission Electron Microscopy; HIF1, Hypoxia Inducible Factor 1; FTIR, Fourier Transform Infrared Resonance; HR-TEM, High Resolution Transmission Electron Microscopy

\section{Introduction}

Nanotechnology has recent biological and medical applications especially in bioanti-VEGFA/GNPs conjugate research. The antiVEGFA/GNPs conjugate based on nanoparticles are introducing materials with new characteristics because sensing elements are biocompatible so it may be cells, proteins, or nucleic acids also the sensors are used to evaluate biological processes changes. Among the nanomaterials used as component in anti-VEGFA/GNPs conjugate, gold nanoparticles (GNPs) have received greatest interests because they have various unique properties. ${ }^{1-6}$ GNPs have been used in various medical applications due to its stability, controlled geometrical, optical, and surface chemical properties. ${ }^{7}$ GNPs have high surface-to-volume ratio and high surface energy that provide a stable immobilization of a large amount of biomolecules retaining their bioactivity. ${ }^{8,9}$ Nanoparticles have a unique characteristics as it not detected by immune system. Nanoparticles play an important role in treatment of some diseases for example, caner, Osteoarthritis (OA) and Rheumatoid Arthritis (RA) diseases through active targeting of angiogenic cells. Osteoarthritis (OA) or degenerative joint disease is the most common type of arthritis. It's usually prevalent among the elderly people; recently it is becoming more common among younger people. The joints most commonly affected are hands, knees, ankles and spines. Often the cause of osteoarthritis is unknown but it may be due to a combination of the following risk factors a family tendency, obesity, a joint injury, repetitive destruction from activities and problems with bones in a joint not lining up properly. ${ }^{10}$ Over many years these factors can wear away the articular cartilage, expose bony surfaces rub together. This along with the growth of bony projections causing swelling, pain and limited movement of the joint. Damage starts at the molecular scale and progressively spreads to the higher structural architecture of the articular cartilage that cushions the joints. ${ }^{11}$

Rheumatoid Arthritis (RA) is the second common type of arthritis and known as an autoimmune disease affecting approximately $1 \%$ of the worldwide population, characterized by the infiltration and accumulation of activated immune cells in the synovial joints. In RA the immune system attacks the joints and organ tissue. Subsequent chronic production of pro-inflammatory cytokines leads to destruction of the joint architecture and severe disability. ${ }^{12,13}$ One of the earliest histopathology responses in RA is the generation of new blood vessels as it is known as Angiogenesis and inflammatory cell recruitment. This event is accompanied by the transudation of fluid and the transmigration of both lymphocytes into the synovium and polymorph nuclear leukocytes into the synovial fluid. ${ }^{14,15}$ In the mature RA synovium, the mass of tissue is too much for the multiple new capillaries to nourish leading to local tissue ischemia. Relative synovial hypoxia is associated with an increased production of the transcription factor hypoxia inducible factor 1 (HIF-1) which activates transcription of genes that are of fundamental importance for angiogenesis, including those for Vascular Endothelial Growth Factor (VEGFA) and the VEGFA receptor.5,16 
The most known rote for treatment of $\mathrm{OA}$ and RA are the use of angiogenesis inhibitors which interfere with various steps in the role of VEGFA binding to its receptor process such as bevacizumab(Avastin $\AA$ ), is a monoclonal antibody that binds to VEGFA antigen. ${ }^{17}$ When VEGFA is attached to bevacizumab, it is unable to activate the VEGF receptor. Also sorafenib and sunitinib, bind to VEGF receptors and blocking their activities. ${ }^{18}$ Recent progresses of the GNPs-labeled antibody or antigen for immunoassay researchers generally accept the theory that mechanisms related to the residues of the particular amino acids play an important role in binding proteins to gold particles. Appropriate active targeting ligand should be selected for designing RA-targeted particles, For example, there are certain biologic drugs, such as anti-Tumor necrosis factor agents or B-cell depleting agents, which target cells other than macrophages. ${ }^{19,20}$ The objective of the present in vitro study is to introduce bioconjugation technique (anti-VEGFA/GNPs conjugate) as novel modality for inhibition of serum VEGFA level for treatment of OA and RA angiogenic diseases.

\section{Materials and methods}

\section{Chemicals}

Gold chloride hydrate $\left(\mathrm{HAuCl}_{4} \cdot \mathrm{H}_{2} \mathrm{O}\right)$, Sodium citrate tribasic dihydrate, Sodium hydrogen bicarbonate, sodium chloride, Bovine Albumin Serum (BSA), Tris buffer (20 mM), Anti-VEGFA polyclonal antibody $(\mathrm{Pab})$ produced in goat $(\mathrm{pH} 7.3)$, sodium azide $\left(\mathrm{NaN}_{3}\right)$ and HUMAN VEGFA ELISA KIT have been purchased from Sigma Aldrich.

\section{Methods}

\section{Preparation of Anti-VEGFA/GNPs conjugate}

Synthesis of GNPs: Synthesis of gold nanoparticles (GNPs) was carried out by the reduction of Gold chloride hydrate by trisodium citrate according to Frens method as follow. ${ }^{21,22}$ In brief; $50 \mathrm{~mL}$ aqueous solution of $0.01 \mathrm{mM} \mathrm{HAuCl}{ }_{4}$ in flask was heated until boiling with stirring. After that $1 \mathrm{~mL}$ of $1 \%$ trisodium citrate solution was added. The solution color turned from yellow to intrinsic bright red. The solution has been left to cool until reach room temperature with gentle stirring. GNPs were characterized by UV-Vis spectroscopy, particle size analyzer, High Resolution Transmission Electron Microscopy (HR-TEM), Fourier Transform Infrared Resonance (FTIR).

Conjugation of Anti-VEGFA and GNPs: The determination of optimum anti-VEGFA-Pab concentration was carried out according to the method described by Ye et al. ${ }^{22,23}$ with modification as follows: Serial dilutions of anti-VEGFA antibody solutions have been prepared $(10,50,100,150,200,250,300$, and $500 \mathrm{ng} / \mathrm{mL})$ in $20 \mathrm{mM}$ tris buffer. Then $10 \mu \mathrm{L}$ from each anti-VEGFA concentration have been added to an eppendorf containing $100 \mu \mathrm{L}$ colloidal gold adjusted to $\mathrm{pH} 7.3$ using $2 \mathrm{M}$ sodium bicarbonate. The anti-VEGFA/GNPs conjugate were allowed to interact for an additional $2 \mathrm{hr}$ at room temperature with gentle shaking. The residual surface of the GNPs was blocked and stabilized by adding $10 \mu \mathrm{L}$ of $1 \%$ BSA in $20 \mathrm{mM}$ tris buffer with stirring for $30 \mathrm{~min}$. The optimum anti-VEGFA concentration estimated using UV-Vis spectroscopy. ${ }^{24}$ and particle size analysis. After determination of antibody optimum concentration for conjugation and functionalization of GNPs, the anti-VEGFA/GNPs conjugate has been prepared at optimum condition as follows; $10 \mathrm{~mL}$ of GNPs adjusted to $\mathrm{pH} 7.3$ was mixed with $1 \mathrm{~mL}$ of anti-VEGFA $(100 \mathrm{ng} / \mathrm{mL})$ and allowed to react for $2 \mathrm{hr}$.

The residual surface of the GNPs was blocked and stabilized by adding $1 \mathrm{~mL}$ of $1 \%$ BSA in $20 \mathrm{mM}$ Tris buffer with stirring for $30 \mathrm{~min}$, and then stored at $4 \circ \mathrm{C}$ for $2 \mathrm{hr}$. After that the anti-VEGFA/GNPs conjugate has been centrifuged (SORVALL -MX-150 centrifuge, Hitachi, Japan) at $10,000 \mathrm{rpm}$ at $4{ }^{\circ} \mathrm{C}$ for $40 \mathrm{~min}$ after that the Supernatant is discarded. The pellet was dispersed in $1 \mathrm{~mL}$ of $20 \mathrm{mM}$ Tris buffer containing $1 \%$ BSA and $0.05 \% \mathrm{NaN}_{3}$. GNPs and Anti-VEGFA/GNPs conjugate have been characterized by an UV-Vis-NIR spectrophotometer (Cary5000 UV-Vis-NIR, Varian Instrument, U.K), Fourier transform infrared spectroscopy (FTIR) NICOLET IS 10 spectrophotometer (Thermo Fisher Scientific, USA), Zetasizer Nanoseries (Malvern Instruments, U.K) and High resolution transmission electron microscopy Tecnai G20 (FEI, Netherlands) operating at $200 \mathrm{kV}$. The characterization procedures and experiments were done at Nanotechnology and Advanced Materials Central Lab, Agriculture Research Center, Egypt.

\section{Participant}

Forty three serum samples have been collected and divided into three groups according to the American College of Rheumatology / The European League Against Rheumatism (ACR/EULAR 2010). ${ }^{25}$ classification criteria as follow. First group, 22 patients with RA disease. Second group,11 patients with primary knee OA upon clinical and radiological criteria of primary OA. Third group, 10 healthy volunteers subjected as control group. All Patients had been selected from the outpatient's clinics and inpatient of Rheumatology department at Ain Shams University Hospital.

\section{Inclusion criteria}

The patients of OA had symptoms and signs consistent with knee $\mathrm{OA}$ and fulfilled the American College of Rheumatology clinical radiological criteria of idiopathic knee OA. The patients after signing a consistent have been included and subjected to the following procedures: Complete medical history, physical examination including body mass index and X-rays of the knee joints.

\section{Excluding criteria}

Patients have been excluded if one at least of the following history were present: knee trauma, Intra-articular steroid of hyaluronate injection within 3 months prior to enrolment, Knee surgery and Arthroscopy and evidence of secondary knee OA.

\section{Ethical consideration}

The nature of the study was explained to all participants. The laboratories represent standard care and pose no ethical conflicts. All patients gave written informed consent to participate in the study, which was approved by the Ain Shams medical ethics committee.

\section{Laboratory Investigations}

Seven $\mathrm{mL}$ of venous blood were withdrawn from all groups and has been divided into three parts; $3 \mathrm{~mL}$ has been putted in a tube with EDTA for complete blood count (CBC) using (BECKMAN COULTER HMXAL) automated differential cell counter, $2 \mathrm{~mL}$ has been putted in sodium citrate tube for estimation of 1sthour erythrocyte sedimentation rate (ESR) using Westergren method. ${ }^{26}$ and $2 \mathrm{~mL}$ has been putted in a plain tube and left to be clotted then centrifuged at $9000 \mathrm{rpm}$ for 5 min for separation of serum after that serum has been stored at $-80{ }^{\circ} \mathrm{C}$ until use in estimation of VEGFA antigen level. VEGFA antigen assay was performed by sandwich ELISA kit. All practical details were operated strictly in accordance with the instructions in the manual of the ELISAkit. ${ }^{27}$

\section{Treatment procedure}

In vitro application of anti-VEGFA/GNPsconjugate to both OA and RA patient serum samples for inhibition of VEGFA antigen, then 
estimation of human serum samples with and without addition of antiVEGFA/GNPs conjugate was carried as follow; $10 \mu \mathrm{L}$ of anti-VEGFA/ GNPs conjugate has been incubated with $100 \mu \mathrm{L}$ of serum, without any dilution of serum, with gentle shaking at room temperature for 2 h.Estimation of the conjugation efficacy evaluated by ELISA kit. ${ }^{27}$ At the same time $10 \mu \mathrm{L}$ of anti-VEGFA antibody $(100 \mathrm{ng} / \mathrm{mL})$ has been incubated with $100 \mu \mathrm{L}$ of patient's serum, without any dilution of serum, with gentle shaking at room temperature for $2 \mathrm{hr}$. Also, 10 $\mu \mathrm{L}$ of GNPs has been incubated with $100 \mu \mathrm{L}$ of patient's serum with gentle shaking at room temperature for $2 \mathrm{hr}$. these procedures have been done to compare the effect of conjugate, anti-VEGFA antibody and GNPs alone on the VEGFA antigen concentration in patient's serum.

\section{Statistical analysis}

Statistical presentation and analysis of the study has been conducted, using the mean, median standard deviation, unpaired student t-test, paired student t-test and linear correlation coefficient tests. Statistical data analyses were performed using GraphPad Prism 5 software.

\section{Results}

\section{Characterization of GNPs and Anti-VEGFA/ GNPsconjugate}

New approach to arthritis inhibition include anti-VEGFA/GNPs conjugate has been designed for inhibition of VEGFA growth factor to serve as a starting point for inhibition of VEGFA-mediated blood vessel proliferation. The conjugation process between GNPs and antiVEFGA antibody is concentration dependent therefore inadequate conditions will lead to precipitation and flocculation of GNPs. VEGFA antibody concentration has a great effect on the conjugation process, where the optimal antibody concentration was found to be $100 \mathrm{ng} /$ $\mathrm{ml}$ as shown in Figure 1A, as these affect the absorbance intensity differences between $520 \mathrm{~nm}$ and $580 \mathrm{~nm}$ of GNPsanti-VEGFA/ GNPs conjugate $\left(\mathrm{A}_{520}-\mathrm{A}_{580}\right)$. In addition to that, at VEGFA antibody concentration of $100 \mathrm{ng} / \mathrm{ml}$, the lowest optimum particle size with no aggregation and better stability of the anti- VEGFA /GNPsantiVEGFA/GNPs conjugate was achieved as observed in Figure 1B. The present study found that $100 \mathrm{ng} / \mathrm{ml}$ VEGFA antibody is the optimum minimum concentration of anti-VEGFA for a stable anti-VEGFA/ GNPs conjugate with about $45 \mathrm{~nm}$ average size. Spectrophotometer measurements of gold nanoparticles GNPs showed sharp characteristic absorption peak at $520 \mathrm{~nm}$ which corresponding to Surface Plasmon Resonance (SPR) absorbance peak, while anti-VEGFA/GNPs conjugate showed slight red shift at $532 \mathrm{~nm}$ as shown in Figure 2A.

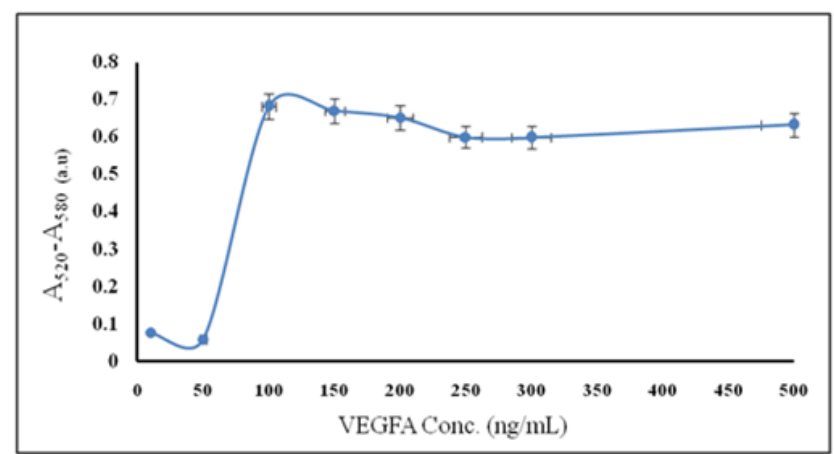

Figure I A Effect of VEGFA concentration in form of absorbance intensity of the conjugate at (A520-A580).

The measurements of particle size distribution based on dynamic light scattering technique. Figure $2 \mathrm{~B}$ shows that average particle size of
GNPs is $18.3 \pm 6.3 \mathrm{~nm}$ with narrow peak, indicating monodispersity and no aggregation. While, the average particle size of anti-VEGFA/ GNPs conjugate is $43 \pm 8.3 \mathrm{~nm}$ with narrow peak, indicating no aggregation formed upon conjugation which indicate particle size growth that support the formation of Anti-VEGFA antibody cap around the gold nanoparticles.

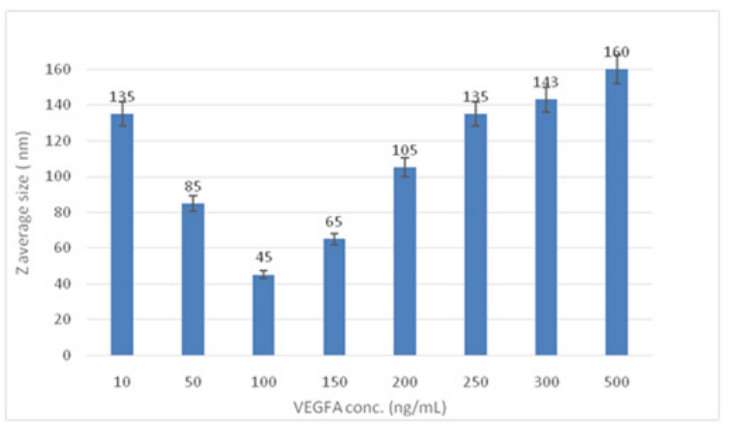

Figure IB Variation of particle size of conjugate upon different VEGFA antibody concentration.

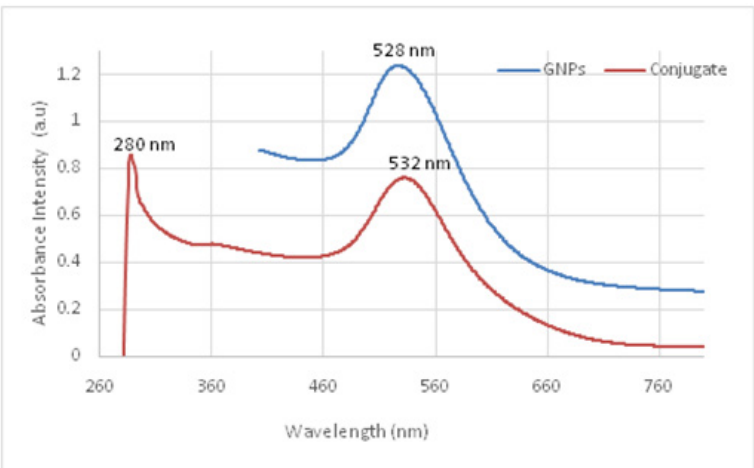

Figure 2AUv-Vis absorption spectrum of GNPs and Anti- VEGFA/GNPs conjugate.

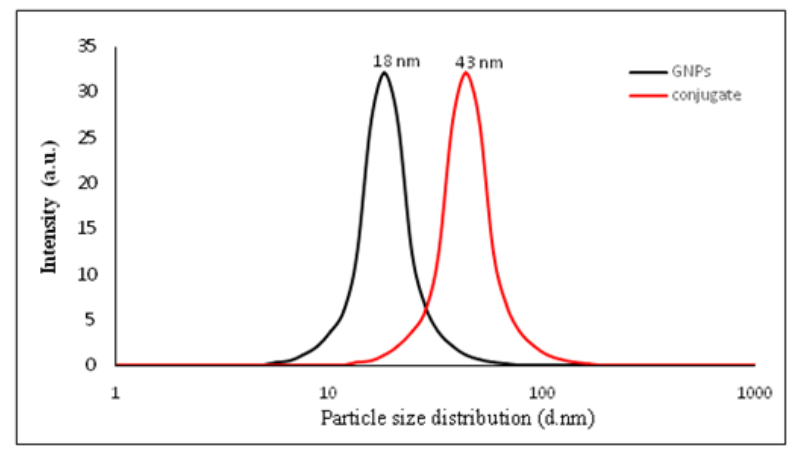

Figure 2B Particles size distribution of GNPs and Anti- VEGFA/GNPs conjugate.

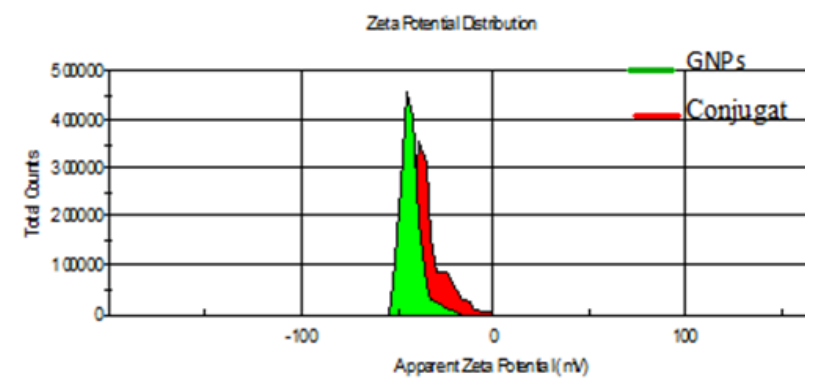

Figure 2CZeta potential distribution of GNPs and Anti- VEGFA/GNPs conjugate. 


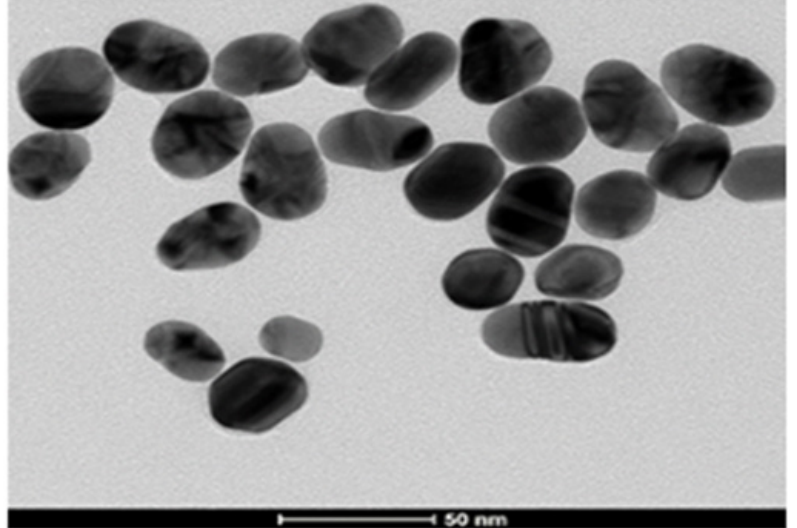

Figure 2D High Resolution Transmission Electron Microscopic (HR-TEM) image of GNPs.

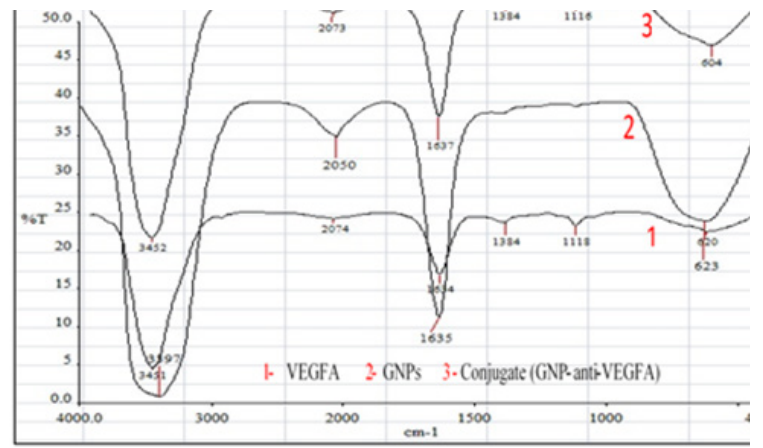

Figure 2E FTIR chart analysis of VEGFA, GNPs and anti-VEGFA/GNPs conjugate.

Zeta potential measurements of GNPs and anti-VEGFA/GNPs conjugate represent a decrease in the net negative charge surround the GNPs upon conjugation with anti-VEGFA according to replace of citrate anions from the dielectric layer surround GNPs with antiVEGFA and keeping the anti-VEGFA/GNPs conjugate stable due to the repulsion between neighbor GNPs. The GNPs surface net charge has been-38.9 mV and the zeta potential for anti-VEGFA/ GNPs conjugate showed a noticeable change in the surface net charge which decreased to the $-25 \mathrm{mV}$ as shown in Figure 2C which also confirm the formation of anti-VEGFA/GNPs conjugate .HR-TEM imaging showed that the formation of spherical gold nanoparticles with average size around $20 \mathrm{~nm}$, as shown in Figure 2D.

A more specific characterization tool that confirm the conjugation formation was FTIR spectrum. FTIR analysis of GNPs showed a broad absorption bands appearing at $623 \mathrm{~cm}^{-1}$ and $1635 \mathrm{~cm}^{-1}$ due to $\mathrm{CH}_{2}-\mathrm{O}$ deformation and $\mathrm{C}-\mathrm{O}$ stretching of citrate ligand in GNPs spectra, FTIR of anti-VEGFA/GNPs conjugate shows presence of peak specific for $\mathrm{C}=\mathrm{C}$ stretching of aromatic amine group which appear at $1116 \mathrm{~cm}^{-1}$ and $1384 \mathrm{~cm}^{-1}$ involve changing in both the band positions and redistribution of intensities, from FTIR spectra of antiVEGFA alone which appear at $1118 \mathrm{~cm}^{-1}$ and $1384 \mathrm{~cm}^{-1}$ upon their adsorption onto GNPs (Figure 2E).

\section{Significance of clinical data}

Laboratory investigations: Serum samples were obtained from 43 patients, First group, 22 patients with RA disease. Second group, 11 patients with primary knee OA upon clinical and radiological criteria of primary OA. Third group, 10 healthy volunteers subjected as control group. The mean age at the time of the study was 35-55 years and the mean duration of the disease was not more than one year. For complete blood count (CBC) parameters, it shows that there is no differences than normal values in OA. In RA patients, the mean value of $\mathrm{Hb}(9 \pm 0.3 \mathrm{~g} / \mathrm{dL})$ were lower than the control patients $(12.5 \pm 0.5 \mathrm{~g} /$ $\mathrm{dL})$, the mean value of WBCs $\left(7.825 \pm 0.610^{3} / \mathrm{mL}\right)$ were higher than those of the control subjects $\left(4.1 \pm 0.2310^{3} / \mathrm{mL}\right)$. In addition to that, the mean value of the Erythrocyte Sedimentation Rate, ESR. In OA patients was $(34.5 \pm 3 \mathrm{~mm} / \mathrm{h})$ while that of RA patients was $(54.5 \pm 5$ $\mathrm{mm} / \mathrm{h}$ ) higher than those of the control $(7 \pm 0.15 \mathrm{~mm} / \mathrm{h})$, as shown in Table 1.

\begin{tabular}{|c|c|c|c|c|c|}
\hline \multirow{2}{*}{$\begin{array}{l}\text { Table I } \\
\text { regarding } \\
\text { (*Significant) }\end{array}$} & $\begin{array}{l}\text { Comparison } \\
\text { complete }\end{array}$ & \multicolumn{2}{|c|}{$\begin{array}{l}\text { between } \\
\text { blood }\end{array}$} & $\begin{array}{l}\text { OA } \\
\text { count }\end{array}$ & $\begin{array}{c}\text { and RA } \\
\text { parameters }\end{array}$ \\
\hline & RA & OA & & & \\
\hline Variable & $\begin{array}{l}\text { (Group I, } \\
\text { no=22) }\end{array}$ & $\begin{array}{l}\text { (Group } \Pi \text {, } \\
\text { no=I I) }\end{array}$ & Control & T-test & P-value \\
\hline Hemoglobin (gm/ & $9 \pm 0.3$ & $11.36 \pm 0.5$ & $12.5 \pm 0.5$ & $\mathrm{t}=0.8976$ & $0.03768 *$ \\
\hline WBCS $(103 / \mathrm{ml})$ & $7.825 \pm 0.6$ & $6.673 \pm 0.7$ & $4.1 \pm 0.23$ & $\mathrm{t}=\mathrm{I} .784$ & 0.2966 \\
\hline ESR $(\mathrm{mm} / \mathrm{h})$ & $54.5 \pm 5$ & $34.5 \pm 3$ & $7 \pm 0.15$ & $\mathrm{t}=2.237$ & $0.05 *>$ \\
\hline
\end{tabular}

\section{Correlations of VEGFA with clinical indicators}

In osteoarthritis patient (OA), there was non-significant correlation in the level of VEGFA with complete blood count (Table 2). While in RA patients there was significant positive correlations in the level of VEGFA with WBCs, High-grade systemic inflammation observed in active RA and significant positive correlations in the level of VEGFA with ESR, useful for monitoring inflammatory diseases especially Rheumatoid Arthritis (Table 3).

Table 2 Correlation coefficient results of VEGFA $(\mathrm{pg} / \mathrm{ml})$ in Osteoarthritis patients versus $\mathrm{CBC}$ (complete blood count) differentiation

\begin{tabular}{lll}
\hline OA & VEGFA $(\mathbf{p g} / \mathrm{ml})$ \\
& R & P-value \\
\hline PLT $(I 03 / \mathrm{mL})$ & 0.295 & 0.378 \\
HB $(\mathrm{g} / \mathrm{dL})$ & 0.105 & 0.759 \\
RBC $(I 06 / \mathrm{mL})$ & $0.06 I$ & 0.859 \\
WBC $(I 03 / \mathrm{mL})$ & 0.22 & 0.516 \\
ESR $(\mathrm{mm} / \mathrm{h})$ & 0.394 & 0.23 \\
\hline
\end{tabular}

Table 3 Correlation coefficient results ofVEGF ( $\mathrm{pg} / \mathrm{ml}$ ) in Rheumatoid arthritis patientsversus CBC (complete blood count) differentiation. (* Significant)

\begin{tabular}{lll}
\hline RA & VEGFA $(\mathrm{pg} / \mathrm{ml})$ & \\
& R & P-value \\
\hline PLT $(I 03 / \mathrm{mL})$ & 0.319 & 0.12 \\
HB $(\mathrm{g} / \mathrm{dL})$ & 0.367 & 0.112 \\
$\operatorname{RBC}(106 / \mathrm{mL})$ & 0.153 & 0.519 \\
WBC $(103 / \mathrm{mL})$ & 0.585 & $0.007^{*}$ \\
ESR $(\mathrm{mm} / \mathrm{h})$ & 0.58 & $0.07^{*}$
\end{tabular}

\section{Effect of treatment on level of VEGFA in patient} serum.

Table $4 \& 5$ represent the individual concentrations of VEGFA in $\mathrm{OA}$ and RA patient's serum, respectively, before and after treatment with anti-VEGFA/GNPs anti-VEGFA/GNPs conjugate, AntiVEGFA and GNPs after incubation for $2 \mathrm{hr}$ the results revealed that the treatment with anti-VEGFA/GNPs conjugate has the highest inhibitory effect on the serum VEGFA concentrations compared to treatment with Anti-VEGFA and GNPs. The inhibitory effect of the anti-VEGFA/GNPs conjugate was directly proportional to the concentration of VEGFA in patient serum irrespective to OA or RA patients. Where for OA patient with highest VEGFA level, $815 \mathrm{pg} /$ 
$\mathrm{ml}$, before treatment, was inhibited to be $299 \mathrm{pg} / \mathrm{ml}, 600 \mathrm{pg} / \mathrm{ml}$ and $800 \mathrm{pg} / \mathrm{ml}$ after treatment with anti-VEGFA/GNPs anti-VEGFA/ GNPs conjugate, Anti VEGFA and GNPs, respectively. While for OA patient with lowest VEGFA level, $68 \mathrm{pg} / \mathrm{ml}$, before treatment, was inhibited to be $55 \mathrm{pg} / \mathrm{ml}, 50 \mathrm{pg} / \mathrm{ml}$ and $60 \mathrm{pg} / \mathrm{ml}$ after treatment with anti-VEGFA/GNPs anti-VEGFA/GNPs conjugate, Anti-VEGFA and GNPs, respectively. For RA patient with highest VEGFA level, 2500 $\mathrm{pg} / \mathrm{ml}$, before treatment, was inhibited to be $952 \mathrm{pg} / \mathrm{ml}, 1500 \mathrm{pg} / \mathrm{ml}$ and $2000 \mathrm{pg} / \mathrm{ml}$ after treatment with anti-VEGFA/GNPs conjugate, Anti VEGFA and GNPs, respectively. While for OA patient with lowest VEGFA level, $55 \mathrm{pg} / \mathrm{ml}$, before treatment, was inhibited to be $27 \mathrm{pg} / \mathrm{ml}, 45 \mathrm{pg} / \mathrm{ml}$ and $50 \mathrm{pg} / \mathrm{ml}$ after treatment with anti-VEGFA/ GNPs conjugate, Anti-VEGFA and GNPs, respectively. It was found that the mean VEGFA concentration in reference group (control) was (30-100) $\mathrm{pg} / \mathrm{ml}$.

Table 4 Inhibitory effect of GNPs, Anti-VEGFA and conjugate on the level of serum VEGFA in Osteoarthritis patients

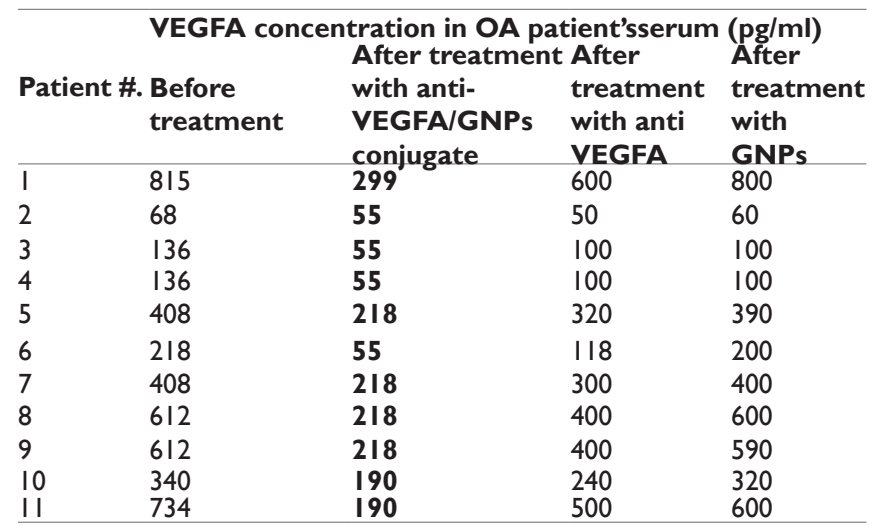

Table 5 Inhibitory effect of treatment with GNPs, Anti-VEGFA and conjugate on the level of serum VEGFA in Rheumatoid Arthritis patients

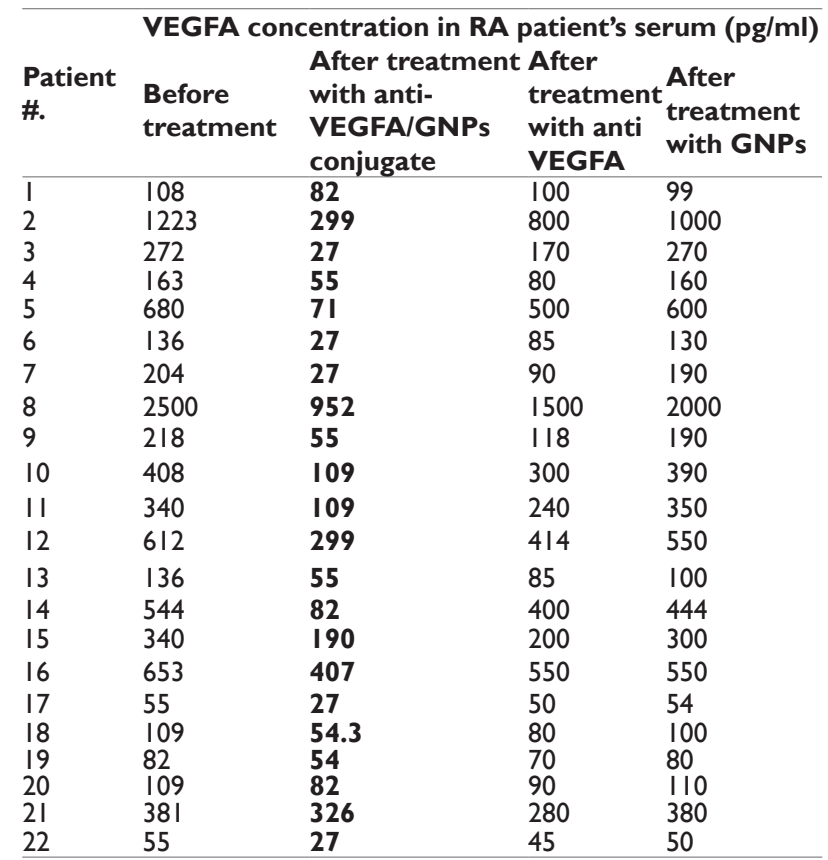

Table 6 summarizes the mean inhibitory effect anti-VEGFA/ GNPs conjugate on the level of VEGFA in both OA and RA patient serum. Results indicate that, significant decrease in VEGFA level after incubation with anti-VEGFA/GNPs anti-VEGFA/GNPs conjugate. The mean concentration of VEGFA in OA patient's serum was (407 \pm 77 $\mathrm{pg} / \mathrm{ml})$ and decreased after incubation of serum with anti-VEGFA/ GNPs conjugate to be $(161 \pm 26 \mathrm{pg} / \mathrm{ml})$. Similar results were obtained for RA patient's serum, where the mean concentration of VEGFA was $(424 \pm 115 \mathrm{pg} / \mathrm{ml})$ and decreased after incubation of serum with antiVEGFA/GNPs anti-VEGFA/GNPs conjugate to be $(155 \pm 44 \mathrm{pg} / \mathrm{ml})$. There is a significant decrease in level of VEGFA after incubation of serum with anti-VEGFA/GNPs conjugate for $2 \mathrm{hr}$ in both OA and RA patient's serum at $\mathrm{p}$ value $=0.001$ and 0.002 , respectively, with mean percent of cure reach to be more than $59 \%$ and $62 \%$ for OA and RA patient's serum, respectively.

Table 6 Descriptive statistics of VEGFA in (Osteoarthritis and Rheumatoid arthritis patients) and compare the level ofVEGFA before and after treatment (*Significant)

\begin{tabular}{|c|c|c|c|c|c|c|c|}
\hline VEGFA (pg/ml) & $\begin{array}{l}\text { Subgroups } \\
\text { OA } \\
\text { Mean }\end{array}$ & \pm & SD & $\begin{array}{l}\text { RA } \\
\text { Mean } \pm\end{array}$ & SD & $\begin{array}{l}\text { T-test } \\
\mathbf{T}\end{array}$ & P-value \\
\hline Before Treatment & 407 & \pm & 77 & $424 \pm$ & 115 & 0.093 & 0.927 \\
\hline After Treatment & 161 & \pm & 26 & 155 & 44 & 0.085 & 0.933 \\
\hline Paired t-test & $<0.001 *$ & & & $0.002 *$ & & & \\
\hline
\end{tabular}

\section{Discussion}

The mean idea behind the present work is to find a new hope to relief the pain of arthritic patients through decreasing the level of VEGFA in serum. The affinity and sensitivity of anti-VEGFA/GNPs conjugate is affected by antibody concentration so that insufficient amount of antibody can lead to aggregation and increased amount will lead to flocculation that have been confirmed by subtraction of absorbance intensity of anti-VEGFA/GNPs conjugate at $\left(\mathrm{A}_{520}-\mathrm{A}_{580}\right)$ as shown in Figure 1A..$^{28}$ Where $A_{520}$ represent SPR absorbance peak of GNPs with no aggregation and $\mathrm{A}_{580}$ represent beginning of aggregation so as the difference between them be great as the optimum anti-VEGFA/GNPs conjugate was obtained without flocculation. ${ }^{29}$ Variation of GNPs particle size distribution, (Figure 1B) with antibody concentrations shows that the anti-VEGFA concentration increases the stability of the GNPs and no aggregation affect the anti-VEGFA/GNPs conjugate until it reaches the minimum antibody concentration that stabilize GNPs, and then excess of the antibody will lead to increase of the size that reflects presence of aggregation and flocculation in the antiVEGFA/GNPs conjugate leading to loss of affinity and sensitivity to antigen. ${ }^{30-34}$

The functionalization of GNPs with anti-VEGFA antibody lead to mild red shift in the absorbance peak of GNPS from $520 \mathrm{~nm}$ to 532 $\mathrm{nm}$ as a function particles size growth due to antibody conjugation, (Figure 2A). Appearance of the characteristic antibody peak exhibited at $280 \mathrm{~nm}$ corresponding to tryptophan group, assure the formation of the anti-VEGFA/GNPs conjugate. ${ }^{35}$

Zeta potential measurements of GNPs and anti-VEGFA/GNPs conjugate, (Figure 2C) the antibody/gold nanoparticles conjugation process. Where the zeta potential of GNPs was $-38.9 \mathrm{mV}$ due to encompassing surface of GNPs with citrate carboxylic groups. Zeta potential of anti-VEGFA/GNPs conjugate was $-25 \mathrm{mV}$ indicates the replacement of the negative charges of citrate ions with the positive charged VEGFA antibody. The type of interaction between antiVEGFA and GNPs was not studied under this study but it may be electrostatic interaction rather than covalent interaction.

FTIR, particle size distribution and HRTEM characterization techniques confirm functionalization and formation of anti-VEGFA/ GNPs conjugate at optimum conditions without aggregation or loss of affinity and sensitivity.

It is known that VEGFA antigen is produced during angiogenesis by rheumatoid synoviocytes and acts specifically on endothelial 
cells. ${ }^{36,37}$ The angiogenesis is important in the development of new cartilage and mineralization in $\mathrm{OA}$ and the neoangiogenesis process contributes to synovitis, pannus formation and articular cartilage destruction in RA. ${ }^{38}$ In RA and OA patients, the mean levels of VEGFA have been significantly higher than in healthy one. Elevated Serum VEGFA was non-significant positively correlated with high WBCs in RA indicating high-grade systemic inflammation in active RA and OA has indeed been associated with the perpetuation of synovial angiogenesis including VEGFA-mediated neovascularization. ${ }^{14}$ Normochromic and normocytic anemia is an extra-articular symptoms of RA. Anemia in RA is multi-factorialdisease activity, drug-induced, nutritional, bone marrow suppression, and ineffective erythropoiesis. Anemia correlates with the disease activity, particularly the degree of articular inflammation. ${ }^{39}$

The nanoconjugation strategy of anti-VEGFA to GNPs surface to which targeting VEGFA specifically over expressed in inflamed cells or in angiogenesis could reduce the side-effects due high level of VEGFA widespread in injured tissues in addition to healthy tissues and organs. ${ }^{40,41}$

The comparison between OA and RA as regarding the effect of anti-VEGFA/GNPs conjugate on VEGFA level antigen shows that a significant decrease in level of VEGFA compared to the anti-VEGFA and GNPs alones as shown in Tables 4\&5. The mean results are summarized in Table 6, where the mean value of VEGFA antigen have been significantly decreased in both RA and OA patients after incubation of serums with anti-VEGFA/GNPs conjugate with cure efficiency more than $60 \%$. The obtained results support the idea of this study which postulate that, anti-VEGFA/GNPs conjugate is highly effective for targeting certain angiogenic factor which may be used for treatment of arthritis disease which confirmed that the targeting of VEGFA is a feasible anti-inflammatory and antiangiogenic therapeutic strategy in arthritis, as well as in malignancies. . $^{14,41,42}$

As the nanoconjugation improve the targeting and the efficacy of antibody in the serum make it more feasible to immune system. It was remarked that treatment efficacy was concentration dependent, for patients with high level of VEGFA, the efficacy of anti-VEGFA/ GNPs conjugate was very high reach to more than $60 \%$ in contrast to that for patients with low level of VEGFA concentration the efficacy was not more than $20 \%$ that may be due to the loading capacity effect. The introduced anti-VEGFA/GNPs conjugate can be used with patients complain of arthritis and will not affect the normal function of VEGFA antigen in blood vessel proliferation in normal situation as a growth factor, that makes the anti-VEGFA/GNPs conjugate verifies the requirements of ideal drugs which works only at high antigen levels as in case of severe arthritis. ${ }^{42,43}$

\section{Conclusion}

Targeting of VEGFA is a feasible anti-inflammatory and antiangiogenic therapeutic strategy in arthritis, as well as in malignancies and could reduce their side-effects. Anti-VEGFA/ GNPs conjugate was highly effective for scavenging VEGFAantigen in serum suppressing its effect and inhibit its interaction with the VEGFA receptors on macrophages and blood vessels. The AntiVEGFA/GNPs conjugate, represented by this work, reduced the level of VEGFAantigen in both OA and RA patients serum (in vitro) at percent $60 \%$ which is considered to be promising approach in arthritis treatment as the traditional treatments is just a combination of drugs for inflammations and relief of pain symptoms.

The work done in this study was on in vitro scale for standardization of the technique. The group welling to apply this product (Anti-
VEGFA/GNPs conjugate) in future for in vivo on animal models as a new modality for treatment of OA and RA patients through decrease level of VEGFA antigen in circulating blood.

\section{Author contribution}

All authors were involved in drafting the article and revising it critically for important intellectual content, and all authors approved the final version to be published. They had full access to all of the data in the study and takes responsibility for the integrity of the data and accuracy of data analysis.

\section{Financial and competing interest disclosure}

The authors have no relevant affiliations or financial involvement with any organization or entity with a financial interest in or financial conflict with the subject matter or materials discussed in the manuscript. This includes employment, honoraria, consultancies, stock ownership or expert testimony, options, grants or patents received or pending, or royalties.

\section{Ackn owledgments}

None.

\section{Conflicts of interest}

None.

\section{References}

1. Radwan SH, Azzazy HM Gold nanoparticles for molecular diagnostics. Expert Rev Mol Diagn. 2009;9(5):511-524.

2. Zhao W, Chiuman W, Lam JC et al. DNA Aptamer Folding on Gold Nanoparticles: From Colloid Chemistry to Biosensors. J Am Chem Soc. 2008;130(11):3610-3618.

3. Popovtzer R Biomedical applications of gold nanomaterials. Nanomedicine. 2014;9(13):1903-1904.

4. Jahnen-Dechent W, Simon U Function follows form: shape complementarity and nanoparticle toxicity. Nanomedicine 2008;3(5):601-603.

5. Duan J, Dong J, Zhang T et al. Polyethyleneimine-functionalized iron oxide nanoparticles for systemic siRNA delivery in experimental arthritis. Nanomedicine. 2014;9(6):789-801.

6. García I, Marradi M, Penadés S Glyconanoparticles: multifunctional nanomaterials for biomedical applications. Nanomedicine. 2010;5(5):777-792.

7. Wang Z, Lee JH, Lu Y Label-Free Colorimetric Detection of Lead Ions with a Nanomolar Detection Limit and Tunable Dynamic Range by using Gold Nanoparticles and DNAzyme. Adv Mater. 2008;20(17): 3263-3267.

8. Wang Z, Ma L Gold nanoparticle probes. Coord Chem Rev. 2009;253(11-12):1607-1618.

9. Jain PK, Lee KS, El-Sayed IH et al. Calculated absorption and scattering properties of gold nanoparticles of different size, shape, and composition: applications in biological imaging and biomedicine. $J$ Phys Chem B. 2006;110(14):7238-7248.

10. Stolz M, Riccardo Gottardi, Roberto Raiteri et al. Early detection of aging cartilage and osteoarthritis in mice and patient samples using atomic force microscopy. Nat Nanotechnol. 2009;4:186-192.

11. Azuma M, Shi M, Danenberg KD et al. Serum lactate dehydrogenase levels and glycolysis significantly correlate with tumor VEGFA and VEGFR expression in metastatic CRC patients. Pharmacogenomics. 2007;8(12):1705-1713. 
12. Thwaites R, Chamberlain G, Sacre S Emerging role of endosomal tolllike receptors in rheumatoid arthritis. Front Immunol 5: 1. 2014

13. Scheinman RI, Trivedi R, Vermillion S, Kompella UB Functionalized STAT1 siRNA nanoparticles regress rheumatoid arthritis in a mouse model. Nanomedicine. 2011;6(10):1669-1682.

14. Szekanecz Z, Besenyei T, Szentpétery A et al. Angiogenesis and vasculogenesis in rheumatoid arthritis. Curr Opin Rheumatol. 2010;22(3):299-306.

15. Samarasinghe RM, Kanwar RK, Kumar K, Kanwar JR Antiarthritic and chondroprotective activity of Lakshadi Guggul in novel alginateenclosed chitosan calcium phosphate nanocarriers. Nanomedicine. 2014;9(6):819-837.

16. McInnes IB, Schett G The pathogenesis of rheumatoid arthritis. $N$ Engl J Med. 2011;365(23):2205-2219.

17. Shih T, Lindley C Bevacizumab: An angiogenesis inhibitor for the treatment of solid malignancies. Clin Ther. 2011;28(11):1779-1802.

18. Gotink KJ, Verheul HMW Anti-angiogenic tyrosine kinase inhibitors: what is their mechanism of action? Angiogenesis. 2010;13(1):1-14.

19. MEASE PJB (Cell-Targeted Therapy in Autoimmune Disease: Rationale, Mechanisms, and Clinical Application. J Rheumatol. 2010;35:1245-1255.

20. Engel P, Gomez-Puerta Ja, Ramos-Casals M, Lozano F, Bosch Therapeutic targeting of $\mathrm{B}$ cells for rheumatic autoimmune diseases. Pharmacol Rev. 2011;63:127-56.

21. FRENS G Controlled Nucleation for the Regulation of the Particle Size in Monodisperse Gold Suspensions. Nature. 1973;241:20-22.

22. Eldin TAS, Elshoky HA, Ali MA Nanobiosensor based on Gold nanoparticles Probe for Aflatoxin B1 detection in food. Int $J$ Curr Microbiol Appl Sci. 2014;3(8): 219-230.

23. Ye Y, Zhou Y, Mo Z, Cheng W, Yang S, et al. Rapid detection of aflatoxin $\mathrm{B}(1)$ on membrane by dot-immunogold filtration assay. Talanta. 2010;81(3):792-798.

24. Wang J, Liu B, Hsu Y, Yu F Sensitive competitive direct enzyme-linked immunosorbent assay and gold nanoparticle immunochromatographic strip for detecting aflatoxin M1 in milk. Food Control. 2011;22:964-969.

25. Aletaha D, Neogi T, Silman AJ et al. Rheumatoid arthritis classification criteria: an American College of Rheumatology/European League against Rheumatism collaborative initiative. Ann Rheum Dis. 2010;69(9):1580-1588.

26. SINTON JR Clinical Value of Some Methods of Estimating Erythrocyte Sedimentation Rate. Br Med J. 1991;1(4547):391-393.

27. Ferrara N, Houck KA, Jakeman LB et al. The vascular endothelial growth factor family of polypeptides. J Cell Biochem. 1991;47(3):211-218.
28. Horisberger M, Rosset J Colloidal gold, a useful marker for transmission and scanning electron microscopy. J Histochem Cytochem. 1977;25(4):295-305.

29. Napper DH Polymeric stabilization of colloidal dispersions. Br Polym J. 1983;18(4):278.

30. Gole A Pepsin-Gold Colloid Anti-VEGFA/GNPs conjugate s: Preparation, Characterization, and Enzymatic Activity. Langmuir. 2001;17:1674-1679.

31. Maruotti N, Annese T, Cantatore FP, Ribatti D Macrophages and angiogenesis in rheumatic diseases. Vasc Cell. 2013;5(1):11.

32. Plebani M, Piva E Use of Fresh Blood for Quality Control. 2012;117(4):621-626.

33. Frieri M Accelerated Atherosclerosis in Systemic Lupus Erythematosus: Role of Proinflammatory Cytokines and Therapeutic Approaches. Curr Allergy Asthma Rep. 2012;12(1):25-32.

34. Kneipp J Surface-Enhanced Raman Scatt. Phys Appl. 2006;335-349.

35. Yoo SA, Kwok SK, Kim WU Proinflammatory role of vascular endothelial growth factor in the pathogenesis of rheumatoid arthritis: prospects for therapeutic intervention. Mediators Inflamm 2008;2008:129873.

36. Nagai T, Sato M, Kobayashi M et al. Bevacizumab an anti-vascular endothelial growth factor antibody, inhibits osteoarthritis. Arthritis Res Ther. 2014;16(5):427.

37. Walsh DA, Bonnet CS, Turner EL, Wilson D, Situ M, et al. Angiogenesis in the synovium and at the osteochondral junction in osteoarthritis. Osteoarthritis Cartilage. 2007;15(7):743-751.

38. Cojocaru M, Cojocaru IM, Silosi I, Vrabie CD, Tanasescu R Extra-articular Manifestations in Rheumatoid Arthritis. Maedica. 2010;5(4):286-291.

39. Loo C, Lowery A, Halas $\mathrm{N}$ et al. Immunotargeted Nanoshells for Integrated Cancer Imaging and Therapy. Nano Lett. 2005;5(4):709-711.

40. Sahoo SK, Parveen S, Panda JJ The present and future of nanotechnology in human health care. Nanomedicine. 2007;3(1):20-31.

41. Kolch W, Martiny-Baron G, Kieser A, Marmé D Regulation of the expression of the VEGF/VPS and its receptors: role in tumor angiogenesis. Breast Cancer Res Treat. 1995;36(2): 139-155.

42. Rodríguez-Rodríguez L, García-Bermúdez M, González-Juanatey C, Vazquez-Rodriguez TR, Miranda-Filloy JA, et al. Vascular endothelial growth factor A and cardiovascular disease in rheumatoid arthritis patients. Tissue Antigens. 2011;77(4):291-297.

43. Ballara SC, Miotla JM, Paleolog EM New vessels, new approaches : angiogenesis as a therapeutic target in musculoskeletal disorders. Int $J$ Exp Pathol. 1999;80(5):235-250. 